\title{
Farmlands Degradation with Intensive Agricultural Practices and Human Health Risk Assessment: A Case Study of Province Punjab, Pakistan
}

Javed Nawab ${ }^{1}$, Sardar Khan ${ }^{2}$, Zia Din ${ }^{1}$, Shah Faisal ${ }^{1}$, Abid Ali ${ }^{1}$, Zia Rahman ${ }^{1}$, Mehboob Alam $^{3}$, Amir Khan ${ }^{2}$, Muhammad Khan ${ }^{2}$, and Attaullah Khan ${ }^{1}$

${ }^{1}$ Abdul Wali Khan University

${ }^{2}$ University of Peshawar

${ }^{3}$ The University of Agriculture Peshawar

November 25, 2020

\begin{abstract}
Farmlands contamination with heavy metals (HMs) can be considered as a global issue especially in developing countries. The current study investigates the various pollution indices, potential ecological risk index (PERI) and human health risk caused by HMs in some selected regions of Punjab Province, Pakistan. Farmlands soil samples were collected, acid extracted and analyzed via ICP-MS (Agilent 7500c) for selected HMs. All the HMs were found within permissible limits set by worldwide regulatory authorities except $\mathrm{Cd}$ which exceeded its limit in $68 \%$ agricultural soils of the study area. The $\mathrm{CF}$ values for Cd showed high (CF[?]6) degree of contamination to considerable contamination (3[?]CF[?]6). The CD values indicated low $(\mathrm{CD}[?] 6)$ contamination to moderate (6dermal>inhalation. Furthermore, the RI values were observed higher than $1.0 \times 10-4$ for Cd (Lahore and Faisalabad regions) and Cr (Multan and Faisalabad regions) in children working in farmlands and likely exposed to high cancer risk. So, minimization of pollutants must be the top priority of the state to reduce contaminants inputs and immobilization in soil through environmental protection laws and regulations
\end{abstract}

\section{Hosted file}

agri soil Paper edited for land degradation and development.pdf available at https: //authorea.com/users/378694/articles/495117-farmlands-degradation-with-intensiveagricultural-practices-and-human-health-risk-assessment-a-case-study-of-province-punjabpakistan 

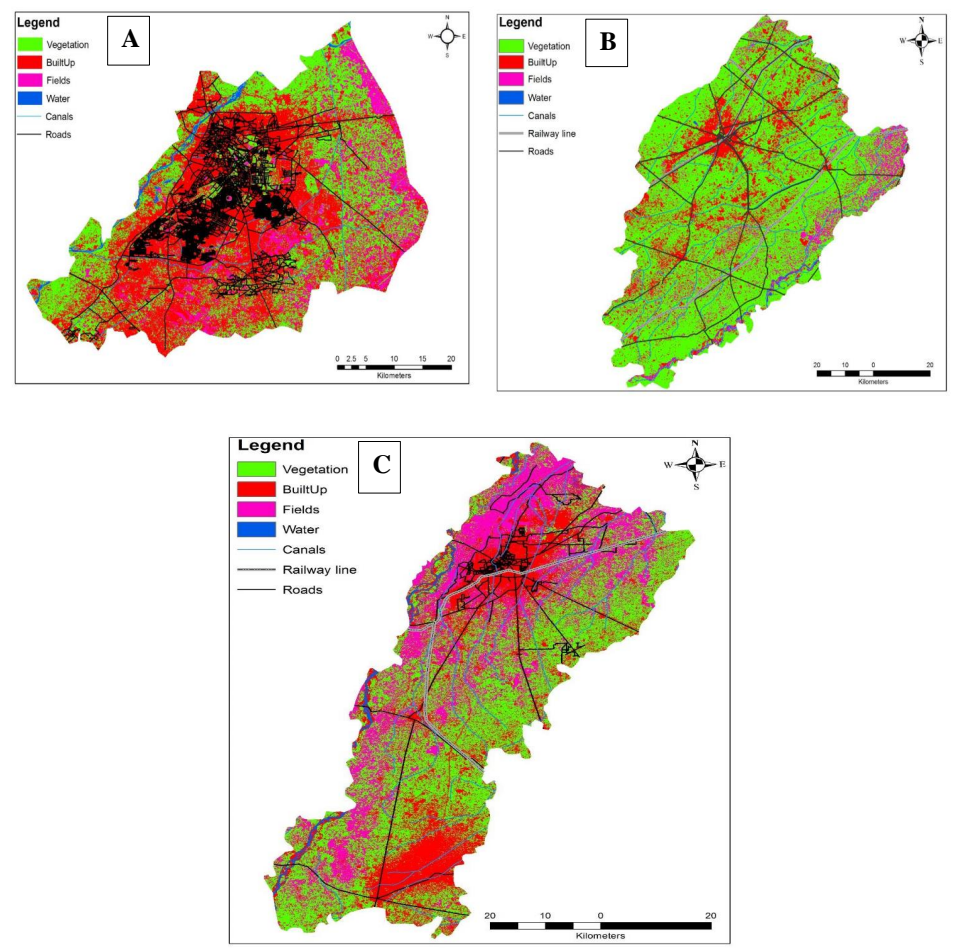

Figure 1. Landcover use map of the study area A) Lahore B) Faisalabad C) Multan

\section{Hosted file}

list of figures.pdf available at https://authorea.com/users/378694/articles/495117-farmlandsdegradation-with-intensive-agricultural-practices-and-human-health-risk-assessment-acase-study-of-province-punjab-pakistan

\section{Hosted file}

list of tables Final.pdf available at https://authorea.com/users/378694/articles/495117farmlands-degradation-with-intensive-agricultural-practices-and-human-health-riskassessment-a-case-study-of-province-punjab-pakistan 